\title{
Human Trichinellosis: Epidemiological Situation in Lithuania, 2008-2017
}

\author{
Saulius Caplinskas ${ }^{1,2^{*}}$, Ausra Bartuliene ${ }^{1}$ and Galina Zagrebneviene ${ }^{1}$
}

${ }^{1}$ Centre for Communicable Diseases and AIDS, Lithuania

${ }^{2}$ Mykolas Romeris University, Lithuania

*Corresponding author: Čaplinskas S, Centre for Communicable Diseases and AIDS, Vilnius, Lithuania, Tel: +37069821173; E-mail: saulius@ulac.It

Received date: January 27, 2018; Accepted date: February 02, 2018; Published date: February 05, 2018

Copyright: (c) 2018 Caplinskas S, et al. This is an open-access article distributed under the terms of the Creative Commons Attribution License, which permits unrestricted use, distribution, and reproduction in any medium, provided the original author and source are credited.

\begin{abstract}
Trichinellosis is an important public health problem in Lithuania. According to the data from the Centre for Communicable Diseases and AIDS, 391 cases of human trichinellosis were reported in Lithuania over the period of 2008-2017, including 13 sporadic cases and 33 outbreaks. The highest incidence rate of infection was recorded among adults. Epidemiological investigation showed that human trichinellosis in Lithuania is transmitted through consumption of infected pork and wild boar meat. $50.4 \%$ of cases of human trichinellosis during the period occurred due to consumption of infected wild boar meat that had not been examined for trichinellosis.
\end{abstract}

Keywords: Human trichinellosis; Lithuania; Trichinella

\section{Introduction}

Trichinellosis is an acute disease found both in humans and animals and caused by roundworms of the genus Trichinella. Human trichinellosis causes high fever, facial edema, myositis and eosinophilia. It can be a serious disease, particularly in elderly patients in whom neurological or cardiovascular complications can lead to death.

Humans become infected after eating raw or undercooked meat of domestic pigs, horses or game containing trichinella larvae.

Trichinosis is a considerable public health problem worldwide and poses an economic threat to livestock producers due to trade restrictions. Although the incidence of this disease has been decreasing since the middle of 20th century, cases of human trichinosis are reported in 55 countries. Worldwide, an estimated 10,000 cases of trichinellosis occur every year [1].

In the period 2011-2015, 1266 cases of confirmed human trichinosis were reported in EU countries, on average 253 cases per year.

In 2015, 243 cases of trichinellosis, 156 of which were confirmed, were reported by 29 EU/EEA countries. The EU/EEA notification rate was 0.03 cases per 100,000 population. Bulgaria, Lithuania and Romania accounted for $63 \%$ of all confirmed cases. Lithuania had the highest notification rate in the EU in 2015, followed by Bulgaria and Romania ( 0.31 and 0.28 cases per 100,000 population, respectively) $[2,3]$.

There are nine types and three genotypes of trichinella described to date in the world. Trichinella is one of the least host-specific parasites in nature and can infect almost any mammalian species, birds and reptiles. Due to different biological properties, the species of trichinae are differently adapted to different hosts and environmental conditions; therefore, their prevalence is limited in certain geographic regions. 4 trichinella species that are prevalent in Europe, as well as in Lithuania, are: T. spiralis, T. nativa, T. britovi, and the nonencapsulating T. pseudospiralis.
The objective of this study is to provide an overview of the current epidemiological situation and the trends of trichinellosis infection in Lithuania in 2008-2017.

\section{Materials and Methods}

Surveillance data from the National Information System of Communicable Diseases and their Agents in the Centre for Communicable Diseases and AIDS and urgent notifications were used for a retrospective descriptive epidemiological analysis of human trichinellosis.

Any cases of diagnosed (suspected) trichinellosis in the personal health care institutions and laboratory identification of trichinellosis agents have to be reported to the Departments of the National Public Health Centre under the Ministry of Health.

Following an urgent notification from a health care institution, the NPHC department specialists start an epidemiological investigation by interviewing patients, their family members and other individuals who have eaten suspected meat. Individuals suspected of having an infection are referred to health care facilities for laboratory testing, medical monitoring and treatment.

CCDA collects and stores the data on trichinellosis (cases and agents) in the National Information System of Communicable Diseases and their Agents, assesses the compatability of the data in the system with notifications, and corrects data discrepancies [4].

\section{Results}

According to the data from the Centre for Communicable Diseases and AIDS, most of the cases were reported in the beginning of the 1990s, with a peak in 1992 and 1994 (21.8 and 19.3 of cases per 100,000 population). Socio-economic changes that occurred in Lithuania over this period led to a significant reduction of large collective farms and restricted the development of private pig farming and related businesses. Some younger private businesses failed to ensure a proper rear and slaughter of pigs, and to prevent an interaction between domestic and wild animals, hence the risk of infection in farmed animals increased. Trichinella infection in pigs 
increased from $0.0027 \%$ to $0.1 \%$ in the year $1981-1985$ and 1993 , respectively. From the year 1993 pig trichinellosis was continuously decreasing [5].

In 2008-2017, a total of 391 cases of trichinellosis were reported involving 33 outbreaks and 13 sporadic cases. Over the decade the incidence of human trichinellosis decreased from 3.44 to 0.07 cases per 100,000 population. The year 2009 and 2010 saw the highest incidence rate (3.44 and 2.31 cases per 100,000 population, respectively). An outbreak due to wild boar meat consumption was reported (107 patients) in 2009, and 4 outbreaks of trichinosis, related to meat of domestic pigs (71 patients) were reported in 2010. The lowest level of incidence was in 2016 (1 patient, i.e., 0.03 cases per 100,000 population) (Figure 1).

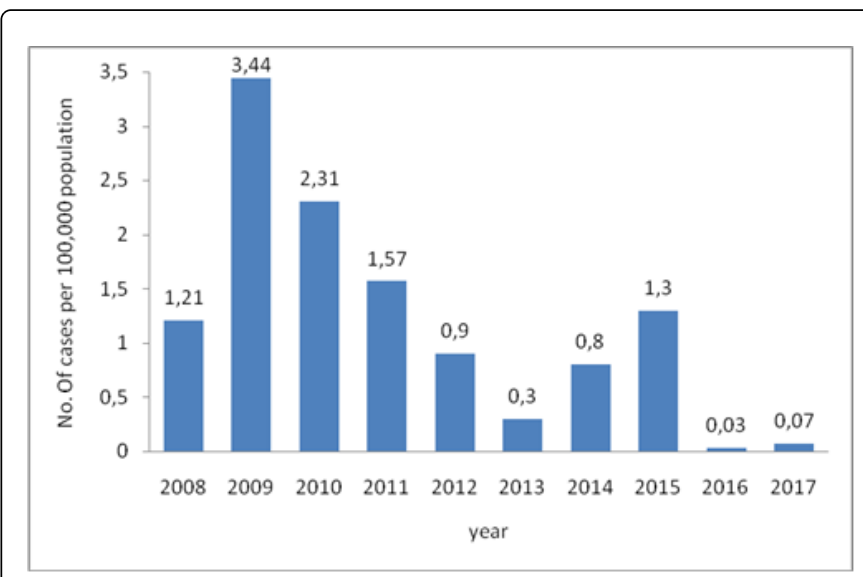

Figure 1: Incidence of human trichinellosis in Lithuania 2008-2017.

People of any profession and age can be affected by trichinellosis, but the highest incidence rate of infection was reported among adults. Rates were highest for persons aged 35-44, although infection cases among children were not rare. Over the last decade (2008-2017), 61 cases (15.6\%) were reported in the age group of under eighteen years (Figure 2). 188 patients with trichinellosis were hospitalised during this period $(48.1 \%)$.

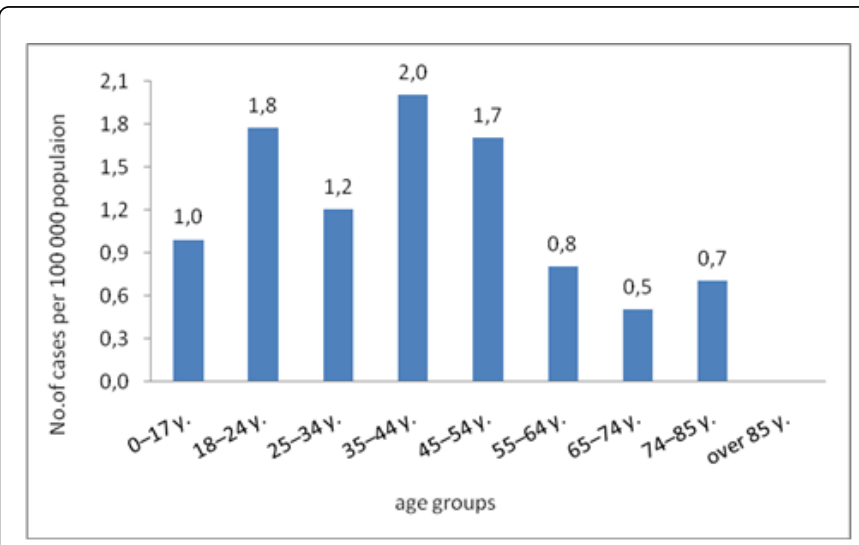

Figure 2: The average incidence of human trichinellosis by age group in Lithuania, 2008-2017.

The incidence rate of trichinellosis in rural population was higher compared to urban population over the period. The average incidence rate of human trichinellosis was 1.7 cases per 100,000 population in rural population, and 1.0 case per 100,000 population in urban population. The average incidence for men was 1.4 cases per 100,000 population, whereas for women it was 1.0 case per 100,000 population (Figure 3).

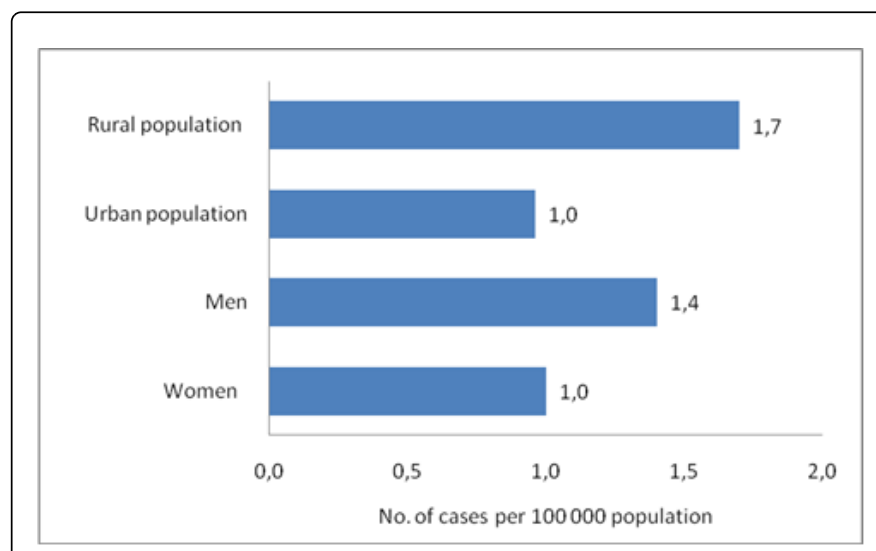

Figure 3: Average incidence of human trichinellosis in rural and urban population, women and men in Lithuania, 2008-2017.

Outbreaks of human trichinellosis (2 or more epidemiologically linked cases) were reported in Lithuania annually. Epidemiological outbreak investigation showed that human trichinellosis in Lithuania was caused by consumption of infected meat of domestic pigs and wild boars. In 2007-2018, family farms where pork was not examined accounted for $57.6 \%$ of trichinellosis outbreaks (19 outbreaks involving 173 infected persons), consumption of infected wild boar accounted for about $33.3 \%$ by (11 outbreaks involving 193 infected persons) and cases with unknown source of infection accounted for $9.1 \%$ (3 outbreaks involving 12 infected persons) (Figure 4).

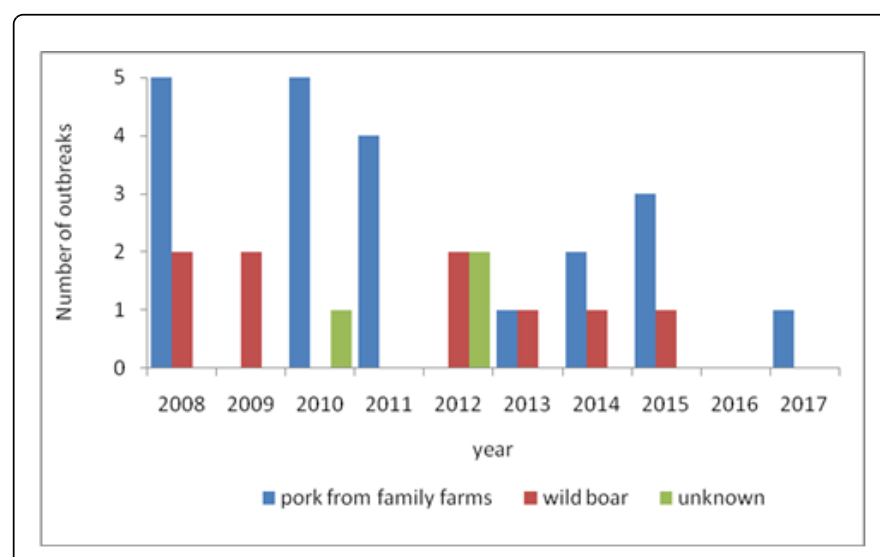

Figure 4: Number of trichinellosis outbreaks by infection source in Lithuania, 2008-2017 ( $n=33)$.

Epidemiological study of the outbreaks of trichinellosis in 2007-2017 showed that 25 outbreaks of human trichinellosis were not limited to family involving 357 people overall (from 2 to 107 cases), and 8 outbreaks were limited to family members involving 21 people overall ( 2 to 5 cases). Wild boar meat was the cause of 9 trichinellosis outbreaks involving 189 people (from 3 to 107 cases). Consumption of pork was the cause of 15 infection outbreaks and involved 162 people 
Page 3 of 4

(from 2 to 33 cases in the area), and there was 1 outbreak involving 10 individuals with unknown source of infection (Figure 5).

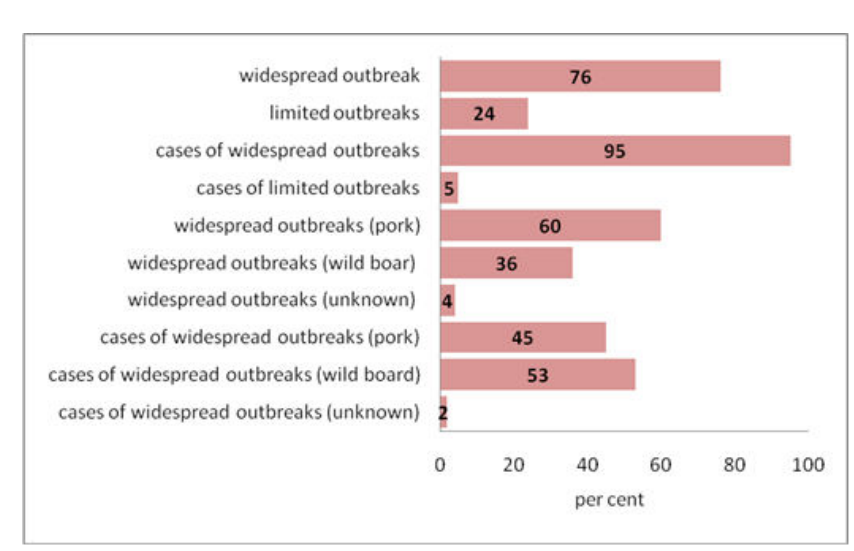

Figure 5: Trichinellosis by infection source in Lithuania, 2008-2017 $(n=33)$.

Human trichinellosis infection outbreaks were mostly reported in central region of Lithuania. In 2008-2017, more than 4 trichinellosis outbreaks were reported in Kaunas regions (Figure 6) [6].

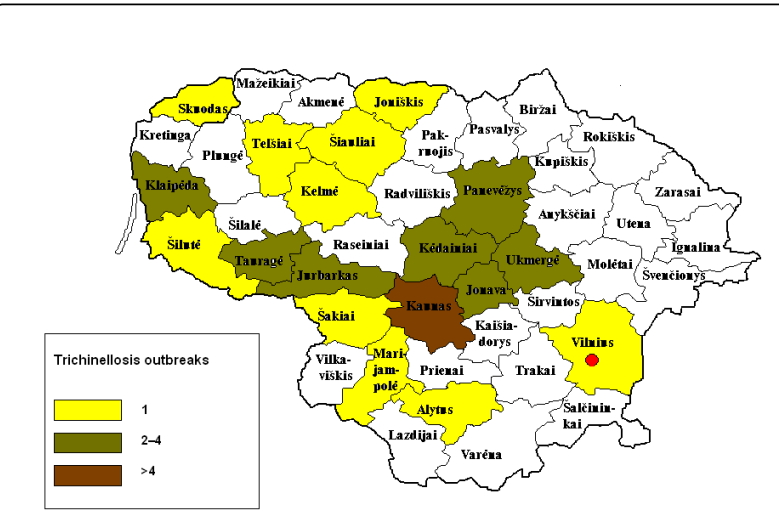

Figure 6: Number of human trichinellosis outbreaks in Lithuania, 2006-2015.

\section{Discussion}

Human trichinellosis is transmitted in Lithuania via infected pork and wild boar meat. Pork and its products remain the main source of human trichinosis, especially the pork from small private farms where biosafety requirements are ignored, where pigs can roam freely in the household with no adequate rodent control, and the meat is prepared at home and is not subject to veterinary inspection.

Consumption of wild boar meat is the second largest cause of trichinellosis in Lithuania. The largest outbreak was registered in 2009, during which 107 persons fell ill with trichinellosis after having eaten infected wild boar meat. The study showed that about $0.5 \%$ of wild boars in Lithuania are infected with trichinella [7]. Infected wild boars live throughout the country; hence wild boar meat is one of the main sources of infection in Lithuania. In accordance with Lithuanian law, the meat of all slaughtered pigs and hunted wild boars must be examined for trichinella. However, in small farms which grow pigs for personal consumption examination is not mandatory. Presently, there are two methods used to detect trichinella in meat: trichinoscopy (digest compressorium technique) and artificial digestion method. Epidemiological data revealed that despite regulations, consumption of uninspected meat is not avoided. Pork in small farms is produced just for personal consumption, not for trade, nevertheless, people in the neighborhood, friends and co-workers often buy such meat, and thus several families may get infected. Therefore, information, especially for small pig breeders and hunters, is needed in order to prevent human trichinellosis in Lithuania.

Large forests in the country allow for a wide variety of wildlife, making it easy for the trichinae life cycle to continue undisturbed. Studies conducted in 2003-2013 showed that trichinellosis is highly prevalent in sylvatic reservoirs, especially among red foxes (Vulpes vulpes) and raccoon dogs (Nyctereutes procyonoides) (40-50\%) [7]. High prevalence of trichinae is caused by a considerable increase in the wildlife population, as well as improper human activity such as inadequate pig keeping, hunting or handling slaughter waste (pigs have contact with corpses of wild animals, farms have a large population of rats and disposal dumps nearby where the carcasses of hunted and slaughtered animals are dumped). Molecular identification revealed 4 trichinella species in Lithuanian wildlife: $T$. spiralis, $T$. nativa, $T$. britovi, and the non-encapsulating $T$. pseudospiralis. It also showed that due to improper human behaviour there is a transmission of trichinella species between domestic and sylvatic cycles in Lithuania [7].

During the last several years no cases of trichinella infection in industrial pig farms were reported; it became infrequent in commercial farms which do not match criteria for industrial farms as well. However, pig infection in small family-run farms is not a rarity. The latter farms are responsible for transmission of $T$. spiralis and the sylvatic T. britovi between domestic and sylvatic cycles [7].

\section{Conclusion}

Incidence of human trichinellosis remains relatively high. Infection incidence was higher in rural poplulations compared to urban populations. Higher incidence of human trichinellosis was registered among adults. The main cause of the outbreaks of human trichinellosis was infected and uninspected pork from small farms and wild boar meat in 2008-2017. Most outbreaks of human trichinellosis were recorded in the central region of Lithuania. Incidence of trichinellosis in humans is decreasing, but due to endemic situation in pig and wild boar populations the risk of infection remains high.

\section{References}

1. Centers for Disease Control and Prevention. Parasites- Trichinellosis.

2. European Centre for Disease Prevention and Control. Annual Epidemiological Report 2016 - Trichinellosis.

3. Devleesschauwe B, Praet N, Speybroeck N, Torgerson PR, Haagsma JA, et al. (2015) The low global burden of trichinellosis: evidence and implications. Int J Parasitol 45: 95-99.

4. Lithuanian Centre for Communicable Disease and AIDS. Statistical report form N 4 Morbidity of infectious diseases. In Lithuanian.

5. Bartuliene A, Jasulaitiene V, Malakauskas A (2005) Human trichinellosis in Lithuania, 1990- 2004. Eurosurveill 10: 2750.

6. Bartuliene A, Liausediene R, Motiejuniene V (2009) Trichinellosis outbreak in Lithuania, Ukmerge region, June 2009. Eurosurveill 14: 19336. 
Citation: Caplinskas S, Bartuliene A, Zagrebneviene G (2018) Human Trichinellosis: Epidemiological Situation in Lithuania, $2008-2017$. Immunochem Immunopathol 4: 130. doi:10.4172/2469-9756.1000130

Page 4 of 4

7. Bartuliene A, Marcinkute A, Virbaliene R, Malakauskas A, Sarkunas M, et al. (2016) Trichineliozès epidemiologinès ir epizootologinès priežiūros metodinès rekomendacijos. Methodical guideline for trichinellosis epidemiological and epizootological surveillance. Vilnius: Lithuanian Centre for Communicable Disease and AIDS; 2016. In Lithuanian. 